Research Article

\title{
High Aldehyde Dehydrogenase Levels Are Detectable in the Serum of Patients with Lung Cancer and May Be Exploited as Screening Biomarkers
}

\author{
Alessandra Rossi $\left(\mathbb{D},{ }^{1,2}\right.$ Minna Voigtlaender, ${ }^{1}$ Hans Klose, ${ }^{1}$ Hartmut Schlüter, ${ }^{3}$ \\ Gerhard Schön, ${ }^{4}$ Sonja Loges, ${ }^{1}$ Moreno Paolini, ${ }^{2}$ Carsten Bokemeyer, ${ }^{1}$ Martin Reck, \\ Giulio Tarro, ${ }^{6,7}$ and Mascha Binder ${ }^{1,0}{ }^{1,8}$ \\ ${ }^{1}$ Department of Oncology, Hematology and Bone Marrow Tansplantation with Section Pneumology, \\ Hubertus University Medical Center Hamburg-Eppendorf, Hubertus Wald Tumorzentrum (University Cancer Center Hamburg), \\ University Medical Center Hamburg, 25 Martinistrasse Str., Hamburg, Germany \\ ${ }^{2}$ Department of Pharmacy and Biotechnologies, Alma Mater Studiorum, University of Bologna, 44 Irnerio Str., Bologna, Italy \\ ${ }^{3}$ Department of Clinical Chemistry, Core Facility Mass Spectrometric Proteomics, University Medical Center Hamburg, \\ 25 Martinistrasse Str., Hamburg, Germany \\ ${ }^{4}$ Department of Medical Biometry and Epidemiology, University Medical Center Hamburg-Eppendorf, 25 Martinistrasse Str., \\ Hamburg, Germany \\ ${ }^{5}$ Department of Thoracic Oncology, LungenClinic Grosshansdorf GmbH, Airway Research Center North (ARCN), \\ Member of the German Centre for Lung Research (DZL), 80 Wöhrendamm Str., Grosshansdorf, Germany \\ ${ }^{6}$ T. \& L. de Beaumont Bonelli Foundation, Naples, 286 Posillipo Str., Naples, Italy \\ ${ }^{7}$ Committee on Biotechnologies and Virus Sphere, World Academy of Biomedical Technologies, UNESCO, Paris, France \\ ${ }^{8}$ Department of Inner Medicine IV, Hematology and Oncology, University Hospital Halle, Ernst-Grube-Str. 40, \\ D-06120 Halle (Saale), Germany
}

Correspondence should be addressed to Mascha Binder; mascha.binder@uk-halle.de

Received 24 December 2018; Revised 20 May 2019; Accepted 4 July 2019; Published 22 August 2019

Guest Editor: Shalini Gupta

Copyright (c) 2019 Alessandra Rossi et al. This is an open access article distributed under the Creative Commons Attribution License, which permits unrestricted use, distribution, and reproduction in any medium, provided the original work is properly cited.

Objectives. Since early detection improves overall survival in lung cancer, identification of screening biomarkers for patients at risk represents an area of intense investigation. Tumor liberated protein (TLP) has been previously described as a tumor-associated antigen (complex) present in the sera from lung cancer patients. Here, we set out to identify the nature of TLP to develop this as a potential biomarker for lung cancer screening. Materials and Methods. Beginning from the peptide epitope RTNKEASI previously identified from the TLP complex, we produced a rabbit anti-RTNKEASI serum and evaluated it in the lung cancer cell line A549 by means of immunoblot and peptide completion assay (PCA). The TLP sequence identification was conducted by mass spectrometry. The detected protein was, then, analyzed in patients with non-small cell lung cancer (NSCLC) and benign lung pathologies and healthy donors, by ELISA. Results. The anti-RTNKEASI antiserum detected and immunoprecipitated a $55 \mathrm{kDa}$ protein band in the lysate of A549 cells identified as aldehyde dehydrogenase isoform 1A1, revealing the molecular nature of at least one component of the previously described TLP complex. Next, we screened blood samples from a non-tumor cohort of 26 patients and 45 NSCLC patients with different disease stages for the presence of ALDH1A1 and global ALDH. This analysis indicated that serum positivity was highly restricted to patients with NSCLC (ALDH $p<0.001$; ALDH1A1 $p=0.028$ ). Interestingly, the global ALDH test resulted positive in more NSCLC samples compared to the ALDH1A1 test, suggesting that other ALDH isoforms might add to the sensitivity of the assay. Conclusion. Our data indicate that ALDH levels are elevated in the sera of NSCLC patients, even with early stage disease, and may thus be evaluated as part of a marker panel for non-invasive detection of NSCLC. 


\section{Introduction}

Despite various treatment approaches such as surgery, radiotherapy, and chemotherapy, lung cancer remains the most common cancer-related cause of death in the world with a $15 \% 5$-year survival rate of about [1-3]. Non-small cell lung cancer (NSCLC) represents the most frequent histology and accounts for $80-85 \%$ of newly diagnosed cases. The standard of care for functionally operable early-stage and resectable stage IIIA NSCLC is surgery which possesses a potential for cure. Nevertheless, only $20 \%$ of NSCLC are diagnosed at early stage and can be resectable; thus, early detection strategies remain an unmet clinical need [4-6].

So far, numerous studies investigated mainly the potential effects of chest X-rays and low-dose helical computed tomography (CT) for imaging alongside with sputum cytology on lung cancer detection. Although these studies showed encouraging results about stage distribution in favor of earlier stage disease, better surgical resection of the tumors, and also an increased survival rate, an improvement on overall mortality could not be determined [7-16]. Serological markers such as Carcinoembryonic antigen (CEA), neuron-specific enolase (NSE), and Cyfra 21-1 are serological markers used for the monitoring of treatment response in lung cancer patients, but their application as screening biomarkers is still a challenging question [17-19]. Theoretically, an ideal biomarker should be $100 \%$ sensitive and specific, a goal that is almost never accomplished. One strategy potentially increasing both parameters is to putting different biomarkers together into a screening marker panel. This approach, along with other noninvasive methods, may allow for further improvement of NSCLC screening [20].

In 1983, a tumor-associated antigen was isolated from NSCLC and named tumor liberated protein (TLP) by Tarro et al. and immunohistochemically localized in small and large granules into the cytoplasm [4, 21-25]. Given that it was also detected in the lumen of atypical glands and in the bronchial secretions of some specimens, TLP could be considered a secretory product of cancer cells. It has been shown that when TLP is isolated and purified from a patient's tumor and reintroduced into the body, it boosts an immune response in the host [4]. Starting from the partial sequence analysis of this protein, corresponding antigenic peptides have been synthetized and used to generate antisera in rabbits. Among the four TLP-derived peptides identified by Tarro, anti-RTNKEASI rabbit sera reacted specifically with NSCLC tumor extracts and sera from lung cancer patients [26]. TLP was detected in the sera of NSCLC patients above all at the early stage of disease.

In this study, we show that TLP (or a component of this putative complex) corresponds to aldehyde dehydrogenase (ALDH) isoform 1A1 (ALDH1A1). ALDHs are a broad family of intracellular enzymes that are involved in cellular detoxification, differentiation, and drug resistance processes by means of the conversion of exogenous and endogenous aldehydes to carboxylic acids [4, 6, 27-30]. Numerous studies have investigated the biological role of ALDH in cancers including breast cancer, colon cancer, head and neck, papillary thyroid carcinoma, and mainly lung cancer, where they have given supportive evidence for the correlation between ALDH activity and lung cancer stem cells [4, 31-37]. Moreover, Cao et al. showed that ALDH1A1 levels were elevated in the sera of NSCLC patients. The combination of serum ALDH1A1 and CEA significantly increased the screening sensitivity of single CEA test [38]. Here, we show that ALDH isoforms other than $1 \mathrm{~A} 1$ may be released into the blood of NSCLC patients, and thus, screening sensitivity may be even more improved by employing an isoform-unspecific global ALDH assay without apparently lowering specificity. Diagnostic sensitivity and specificity will, however, have to be prospectively validated in larger cohorts of patients with early-stage NSCLC and in healthy subjects at risk for NSCLC as well as in other cancer patient cohorts.

\section{Materials and Methods}

2.1. Patient Characteristics and Materials. Blood samples from 45 newly diagnosed NSCLC patients, 17 patients with benign lung pathologies, and 9 healthy donors were collected during routine diagnostic workup. The work has been carried out in accordance with the declaration of Helsinki. All patients consented to the use of their biological material for this investigation as approved by the Landesärztekammer Hamburg (ethics committee) (project number PV4382). Patients with lung cancer stages I-IIIA were considered as early-stage disease, as previously published [30]. Clinical characteristics (type of lung cancer, patient age, sex, smoking, tumor histology, tumor stage, and secondary diagnosis) of this cohort are displayed in Table 1.

2.2. Antigen Synthesis and Antibody Production. The production of two different rabbit polyclonal anti-RTNKEASI immune sera and the synthesis of TLP-derived peptide RTNKEASI [26] were both conducted at Rockland Immunochemicals Inc. (Gilbertsville, PA, USA) and at BioGenes GmbH (Berlin, Germany). We further purified the anti-RTNKEASI immune serum produced at Rockland by means of chromatography against the RTNKEASI peptide.

2.3. Cell Culture. The human cell lines MRC-5, A549, Hela, CA46, HL60, PC3, and MCF-7 were obtained from American Type Culture Collection (ATCC; Manassas, VA, USA). Cell lines were cultured at $37^{\circ} \mathrm{C}$ in a humidified atmosphere of $5 \% \mathrm{CO}_{2}$ in air under the following conditions: CA46 cell line in Glutamax RPMI 1640; PC3 cell line in Glutamax HAM's F-12; MRC-5, HL60, MCF-7, A549, and Hela cell lines in Glutamax Dulbecco's Modified Eagle's Medium. All the media (Gibco, Life Technologies) were supplemented with 10\% fetal bovine serum (Biochrom GmbH, Berlin, Germany) [39].

2.4. Western Blot. We prepared cell pellets and lysates from MCF-7, CA46, HL60, PC3 MRC-5, A549, and Hela cell lines as described previously $[39,40]$. 
TABLE 1: Baseline characteristics of all patients and healthy controls.

\begin{tabular}{|c|c|c|c|c|}
\hline & $\begin{array}{c}\text { Healthy } \\
\text { controls }(n=9)\end{array}$ & $\begin{array}{c}\text { Benign lung } \\
\text { disease }(n=17)\end{array}$ & $\begin{array}{l}\text { Early-stage lung } \\
\text { cancer }(n=25)\end{array}$ & $\begin{array}{l}\text { Advanced-stage lung } \\
\text { cancer }(n=20)\end{array}$ \\
\hline Age in years, mean $\pm S D$ & $42.7 \pm 18.0$ & $53.1 \pm 18.3$ & $68.5 \pm 8.2$ & $62.3 \pm 8.8$ \\
\hline Male, no. (\%) & $2(22.2)$ & $10(58.8)$ & $12(48.0)$ & $10(50)$ \\
\hline Smoker, no. (\%) & 0 & $11(64.7)$ & $20(80.0)$ & $15(88.0)^{*}$ \\
\hline Smoking in pack-years, mean \pm SD & 0 & $28.4 \pm 29.5$ & $43.6 \pm 30.6$ & $47.3 \pm 22.05$ \\
\hline \multicolumn{5}{|l|}{ Type of lung cancer, no. (\%) } \\
\hline NSCLC & & & $25(100.0)$ & $20(100.0)$ \\
\hline Adenocarcinoma & & & $15(60.0)$ & $13(65)$ \\
\hline Squamous cell carcinoma & & & $8(32.0)$ & $2(10)$ \\
\hline Large cell carcinoma & & & $2(8.0)$ & $1(5)$ \\
\hline \multicolumn{5}{|l|}{ UICC classification, no. (\%) } \\
\hline IA & & & $5(20.0)$ & \\
\hline IB & & & $8(32.0)$ & \\
\hline IIA & & & $6(24.0)$ & \\
\hline IIB & & & $5(20.0)$ & \\
\hline IIIA & & & $1(4.0)$ & \\
\hline IIIB & & & & $1(5.0)$ \\
\hline IV & & & & $15(75.0)$ \\
\hline \multicolumn{5}{|l|}{ Type of benign lung diseases, no. (\%) } \\
\hline COPD & & $8(47.1)$ & & \\
\hline Cystic fibrosis & & $4(23.5)$ & & \\
\hline Other benign lung diseases** & & $5(29.4)$ & & \\
\hline
\end{tabular}

NSCLC: non-small cell lung cancer; COPD: chronic obstructive pulmonary disease. ${ }^{*}$ Smoking status of 3 patients unknown. ${ }^{* *}$ Other benign lung diseases comprise precapillary pulmonary hypertension $(n=2)$, interstitial lung disease $(n=1)$, sarcoidosis $(n=1)$, and mucoid impaction $(n=1)$.

Cell culture supernatant from A549 cells $\left(5 \times 10^{6}\right)$ was treated on ice with $10 \%$ trichloroacetic acid (TCA) and then incubated with ice-cold $90 \%$ acetone at $-20^{\circ} \mathrm{C}$. Subsequently, the sample was centrifuged and the pellet dried at $65^{\circ} \mathrm{C}$ for 30 minutes.

The isolated proteins were mixed in Laemmli sample buffer (20\% glycerol, $4 \%$ sodium dodecyl sulfate (SDS), $100 \mathrm{mM}$ Tris-HCl, $200 \mathrm{mM}$ dithiothreitol (DTT), and $0.01 \%$ bromophenol blue) and boiled before loading into SDSPAGE gel. Finally, the proteins were blotted onto membranes and blocked in nonfat dry milk $8 \%+$ PBS $+0.1 \%$ Tween-20 before hybridization with the anti-RTNKEASI serum diluted $1: 1000$ in PBS $+0.1 \%$ Tween-20+BSA 5\% buffer or $\beta$-actin 1:20000 (Biolegend, San Diego, CA), overnight at $4^{\circ} \mathrm{C}$. After primary antibodies, the membranes were probed with a secondary antibody $(1: 30000$ in PBS $+0.1 \%$ Tween $-20+$ BSA 5\%), and then, proteins were visualized by enhanced chemiluminescence (GE Healthcare, Little Chalfont, UK).

2.5. PCA. The anti-RTNKEASI serum $(1: 1000)$ was subjected to preincubation with peptide RTNKEASI (500fold molar excess) or KDSGNEQTFLPP as a control peptide, before hybridization with blotted A549 sample for 2 hours, according to Rockland procedure. The membranes were probed with a secondary antibody, and immunoreactive bands were detected by enhanced chemiluminescence.

2.6. 2D Polyacrylamide Gel Electrophoresis. Protein isolation from cell lines was performed as described previously [41]. For the first dimension isoelectric focusing, we used $7 \mathrm{~cm}$ immobilized $\mathrm{pH}$ gradient (IPG) dry strips with a linear $\mathrm{pH}$ 4-7 gradient (GE Healthcare). Solubilized proteins $(50 \mu \mathrm{g})$ were put onto the strips, rehydrated, and incubated over night [41]. Proteins were resolved by the PROTEAN IEF system (Bio-Rad) (voltage gradient at $20^{\circ} \mathrm{C}$ with a current limit of $50 \mu \mathrm{A}$ ) under the following conditions: $4 \mathrm{~h}$ at $250 \mathrm{~V}$, $8000 \mathrm{~V}$ linear gradient to $15000 \mathrm{~V} \cdot \mathrm{h}$, and rapid $8000 \mathrm{~V}$ to $75000 \mathrm{~V} \mathrm{~h}$, for a total of $90 \mathrm{kV} \cdot \mathrm{h}$ [41]. After equilibration in buffer 1 (130 mM DTT, $6 \mathrm{M}$ urea, 20\% glycerol, 0.05 M Tris$\mathrm{HCl}, 2 \% \mathrm{SDS}$ ) and buffer 2 containing iodoacetamide in place of DTT, the first dimension strips were positioned to the upper part of $8 \%$ acrylamide (Applichem $\mathrm{GmbH}$, Darmstadt, Germany), for performing the second dimension [41]. The separated proteins were stained by silver or blotted onto the membrane and probed with the preserum or anti-RTNKEASI serum.

2.7. Protein Identification by $L C-M S / M S$. The gel spots were treated with DTT $\left(10 \mathrm{mM}, 56^{\circ} \mathrm{C}, 30 \mathrm{~min}\right)$ and with iodoacetamide $(55 \mathrm{mM}$, at room temperature, $20 \mathrm{~min}$, in the dark). Subsequently, the proteins were digested by $13 \mathrm{ng} / \mu \mathrm{l}$ trypsin (sequencing grade modified trypsin, Promega) in $50 \mathrm{mM}$ ammonium bicarbonate, $37^{\circ} \mathrm{C}, 16 \mathrm{~h}$. Tryptic digested peptides were extracted in $65 \%$ acetonitrile $(\mathrm{ACN}) / 5 \%$ formic acid (FA), vacuum-dried, and dissolved in $15 \mu \mathrm{L} 0.1 \%$ FA. Tryptic digested peptides were separated on an UltiMate 3000 Rapid Separation liquid chromatography (RSLC) system (Dionex, Thermo Scientific, Bremen, Germany) coupled online via electrospray-ionization (ESI) to an Orbitrap Fusion Tribrid mass spectrometer (Thermo Scientific, Bremen, Germany). The samples were loaded with a flow rate of $5 \mu \mathrm{l} / \mathrm{min}$ on a trapping column (Acclaim PepMap 
$\mu$-precolumn, C18, $300 \mu \mathrm{m} \times 5 \mathrm{~mm}, 5 \mu \mathrm{m}, 100 \AA \AA$, Thermo Scientific, Bremen, Germany; nanoACQUITY-UPLC Symmetry C18 trap column, $180 \mu \mathrm{m} \times 20 \mathrm{~mm}, 5 \mu \mathrm{m}, 100 \AA \hat{A}$; buffer A: $0.1 \%$ FA in HPLC- $\mathrm{H}_{2} \mathrm{O}$; buffer B: $0.1 \%$ FA in $\mathrm{ACN}$ ) with $2 \%$ buffer $\mathrm{B}$. The loaded samples on the trapping column were washed firstly for $5 \mathrm{~min}$ with $2 \%$ buffer B $(5 \mu \mathrm{l} / \mathrm{min})$ and subsequently the peptides were eluted $(200 \mathrm{nl} / \mathrm{min})$ onto the separation column. Tryptic digested peptides were separated on a reversed-phase C18 column (Acclaim PepMap 100, $75 \mu \mathrm{m} \times 25 \mathrm{~mm}, 2 \mu \mathrm{m}, 100 \AA$; Thermo Scientific, Bremen, Germany; nanoACQUITY-UPLC column, BEH 130 C18, Waters; $75 \mu \mathrm{m} \times 250 \mathrm{~mm}, 1.7 \mu \mathrm{m}, 100 \AA \hat{\text { }}$ ) with a flow rate $200 \mathrm{nl} / \mu \mathrm{m}$ with a binary buffer system of solvent $\mathrm{A}(0.1 \% \mathrm{FA}$ in HPLC- $\left.\mathrm{H}_{2} \mathrm{O}\right)$ and solvent $\mathrm{B}(0.1 \% \mathrm{FA}$ in ACN). The peptides were eluted with a gradient of $2-30 \%$ Solvent B in 30 min. MS analysis was performed in the positive ion mode and was programmed to acquire by data-dependent mode (DDA). The full scans were acquired in the Orbitrap mass analyzer of Fusion with a resolution of 120,000 FWHM at $\mathrm{m} / z 200$ on the MS level over a $\mathrm{m} / \mathrm{z}$ range from 400 to 1500 (maximum injection time: $50 \mathrm{~ms}$ and automatic gain control target: $4 e 5$ ). The fragmentation was carried out with an intensity threshold of $1 e 4$, and the fragmented ions were accumulated in the linear ion trap in the rapid mode. Only precursors with charge states between +2 and +5 and the most intense precursors were selected for fragmentation. The top intense ions were isolated to a target value of $1 e 4$ with a maximum injection time of 50-150 ms. The raw data were processed with Proteome Discoverer, v1.4.1.14 (Thermo Scientific). Protein identification was performed by using UniProt FASTA database.

2.8. ALDH and ALDH1A1 ELISA Assay. Serum samples from patients with NSCLC and benign lung pathologies and healthy donors were collected and stored at $-80^{\circ} \mathrm{C}$. The sera were subsequently assayed according to the manual instructions of the global ALDH ELISA kit with a monoclonal antibody specific for different ALDH isoforms (Bluegene, Biotech, Shanghai, China) and the ALDH1A1 ELISA kit with a monoclonal antibody specific for the isoform 1A1 (Cloud-Clone Corp. Houston, TX, USA). Three independent sera patients' samples are analyzed. Data are expressed as means \pm SD of 3 independent experiments.

2.9. Statistics. Data were presented as means \pm standard deviation (SD). We used backward stepwise linear-regression modelling to analyze differences in the ALDH- and ALDH1A1 serum levels, respectively, between patients with and without NSCLC under consideration of age, sex, and smoking (in pack-years). Correlation coefficients were according to the method of Pearson. All analyses were carried out using IBM $^{\circledR}{ }^{\circledR}$ SPSS $^{\circledR}$ version 22 or GraphPad Prism $^{\mathrm{TM}}$ version 5 software. A $p$ value of $<0.05$ was considered statistically significant.

\section{Results}

3.1. Peptide RTNKEASI Mimics a $55 \mathrm{kDa}$ Protein Highly Expressed in Lung Cancer Cell Line A549. To identify the complete protein sequence or major component of TLP, we produced two polyclonal antibody sera (BioGenes $\mathrm{GmbH}$, Berlin, Germany; Rockland Immunochemicals, PA, USA) by using the peptide epitope mimic RTNKEASI derived from TLP as previously published [25]. Compared to the preimmune sera, both anti-RTNKEASI sera detected one differential protein band in the NSCLC cell line A549 at $55 \mathrm{kDa}$ (Figures 1(a) and 1(b)).

Based on these results, we performed a peptide competition assay (PCA) with limiting concentrations of detection antiserum and an excess of blocking RTNKEASI or control peptide. A partial extinction of the $55 \mathrm{kDa}$ protein band in the presence of the specifically blocking RTNKEASI peptide compared to the control peptide confirmed that the $55 \mathrm{kDa}$ band was specifically recognized by RTNKEASIdirected antibodies from the antiserum (Figure 1(c)).

In order to analyze specificity of the $55 \mathrm{kDa}$ protein for lung cancer, we subjected protein lysates from a variety of tumor cell lines and normal lung tissue to western blot analysis with the anti-RTNKEASI serum. Our western blot results showed very high levels of this $55 \mathrm{kDa}$ protein in the lung cancer cell line A549, whereas all other cell lines showed either no or faint bands at $55 \mathrm{kDa}$ (Figure 2(a)).

We also analyzed the supernatant from A549 cell line to verify cell ability to secrete ALDH outside. Our western blot showed a specific band at $55 \mathrm{kDa}$ with a considerable amount of this protein corresponding to ALDH, as confirmed by mass spectrometry analysis (Figure 2(b) and Table 2).

3.2. Mass Spectrometric Identification of ALDH1A1 as Parental Antigen Mimicked by Peptide RTNKEASI. In order to identify the $55 \mathrm{kDa}$ protein by mass spectrometry (MS), we conducted a two-dimensional (2D) gel electrophoresis of protein extracts from A549 and MCF-7 (negative control) followed by western blotting and detection with the antiRTNKEASI serum (Figure 3). We observed two neighboring spots at the same molecular weight of $55 \mathrm{kDa}$ but with slightly different isoelectric points, 6.54 and 6.73 respectively, which exhibited reactivity with the antiRTNKEASI serum. These spots were neither detected by the preimmune serum nor by the anti-RTNKEASI serum in the control cell lysate (Figure 3). These two spots were matched to and excised from 2D protein gels followed by MS. Our results showed that the $55 \mathrm{kDa}$ protein corresponds to ALDH isoform 1A1 which is highly expressed in different tumors including NSCLC. This result was also confirmed by MS of one dimensionally (1D) separated protein extracts from A549 cells, A549 cell culture supernatant, and immunprecipitations with anti-RTNKEASI serum from the A549 lysate (Table 2). Sequence alignment of ALDH1A1 with the peptide RTNKEASI revealed no linear matches, suggesting that this peptide only structurally mimics ALDH1A1.

3.3. Detection of ALDH1A1 and Global ALDH in Sera of Patients with Lung Cancer and Benign Lung Pathologies. 


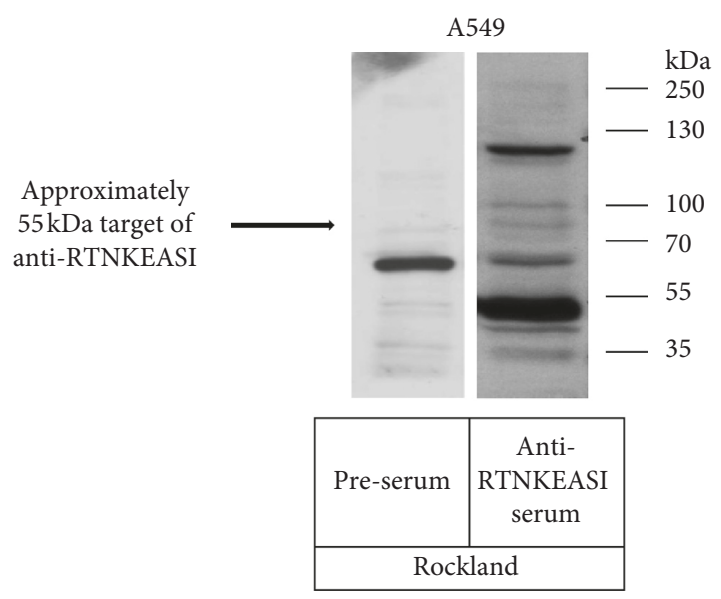

(a)

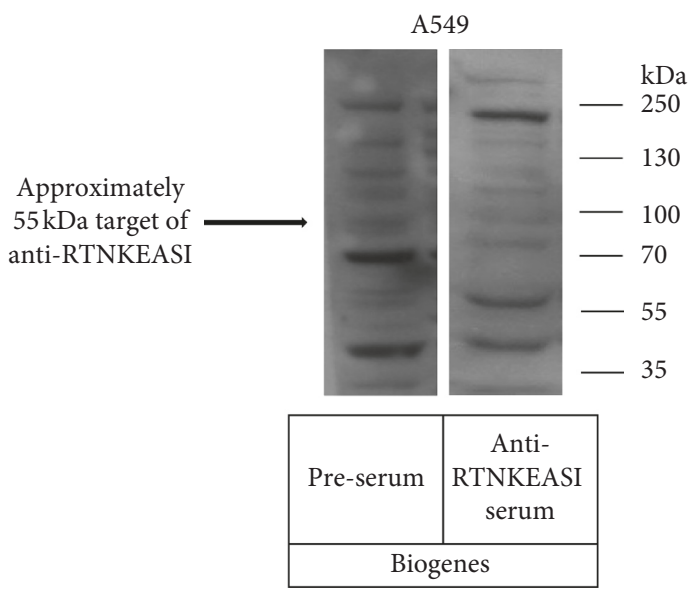

(b)

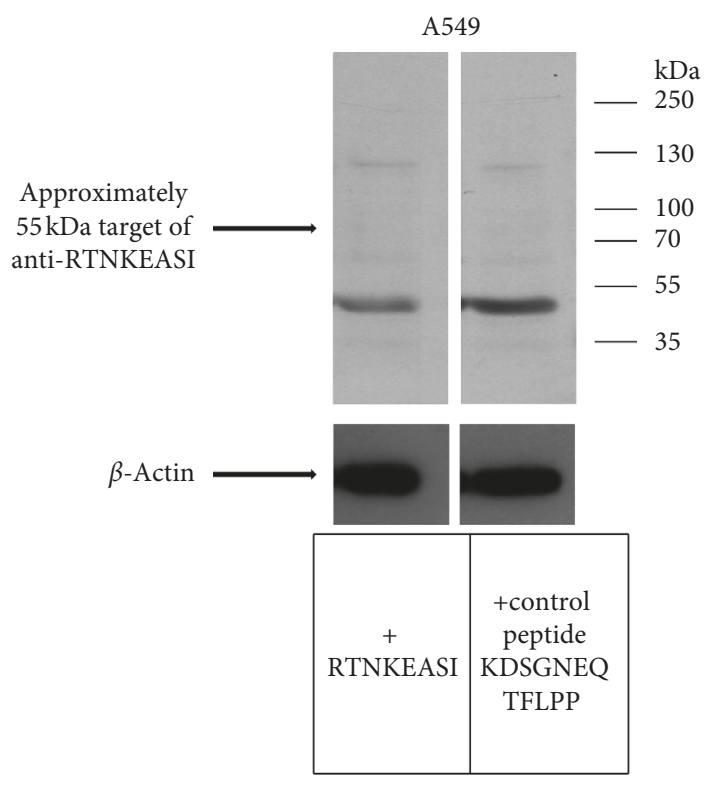

(c)

FIGURE 1: Western blot analysis of the polyclonal anti-RTNKEASI serum in A549 cell line. SDS gel was loaded with protein extract from non-small cell lung cancer A549 cell line followed by electrophoresis and immunoblotting. The blots were incubated with the preimmune serum and the polyclonal anti-RTNKEASI serum produced in rabbits from Rockland (a) or BioGenes (b). The $55 \mathrm{kDa}$ target of antiRTNKEASI appears only in sera of animals after immunization, and it is absent in the presera from the same rabbit. These results were confirmed with both Rockland and BioGenes antibodies. A PCA was performed by incubating the corresponding blots with the polyclonal anti-RTNKEASI serum from Rockland, pretreated with or without the peptide RTNKEASI (c) and also $\beta$-actin, as endogenous control. The intensity of the band approximately at $55 \mathrm{kDa}$ detected by the secondary anti-rabbit horseradish peroxidase-conjugated was reduced after the preincubation of the antibody with the peptide RTNKEASI.

To explore the utility of serum ALDH1A1 as potential biomarker for lung cancer, we tested ALDH1A1 protein levels in sera from 25 NSCLC patients with early-stage disease, 20 NSCLC patients with advanced stage disease, 17 patients with nonneoplastic pulmonary diseases and 9 healthy donors. The baseline characteristics of this cohort are shown in Table 1. We compared ALDH serum levels in NSCLC patients with benign lung pathologies and healthy donors groups as negative controls to set the threshold of background and normalize the measurements, according to previous studies [42-44]. We found ALDH1A1 serum levels above a sensitivity threshold of $10 \mathrm{ng} / \mathrm{ml}$ (reflecting the estimated background noise) in only three of 45 NSCLC patients (6.7\%), while all other NSCLC patients showed ALDH1A1 serum levels comparable with the control cohorts (Figures 4(a) and 4(b)). However, after precluding age, sex, and smoking (in pack-years) as nonsignificant parameters associated with the concentration of ALDH1A1 in the backward stepwise linear-regression analysis, overall, ALDH1A1 serum levels differed significantly between the lung cancer and the no-lung cancer patient groups. The mean difference in the ALDH1A1 concentration between no lung cancer and lung cancer is $2.10 \mathrm{ng} / \mathrm{ml}, 95 \%$ CI: $0.23 \mathrm{ng} / \mathrm{ml}$ to $3.98 \mathrm{ng} / \mathrm{ml} ; p=0.028$. 

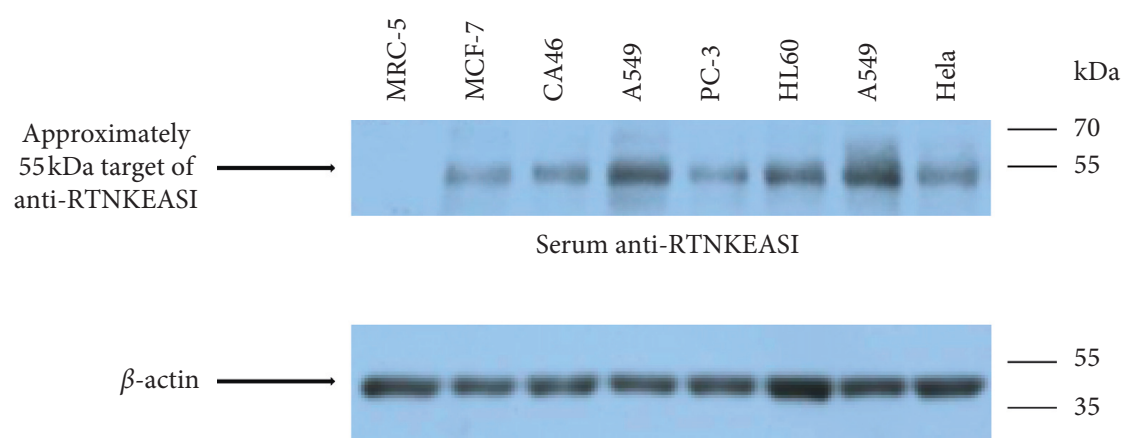

(a)

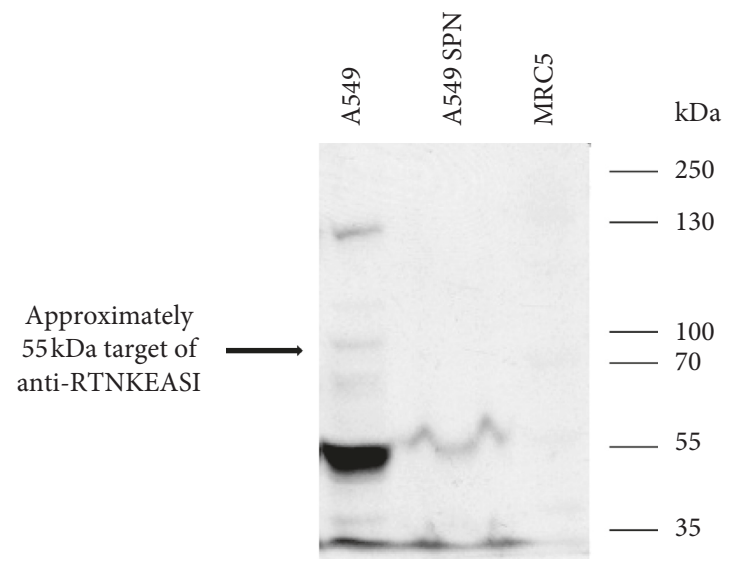

(b)

Figure 2: Western blot analysis for the polyclonal anti-RTNKEASI serum in cancer cell lines and cellular supernatant. (a) Protein extracts from non-small cell lung cancer A549, normal lung tissue MRC-5, Burkitt lymphoma CA46, leukemia HL60, breast cancer MCF-7, cervical carcinoma Hela, and prostate cancer PC-3 cell lines were loaded into SDS gel and subjected to electrophoresis and immunoblotting with the polyclonal anti-RTNKEASI serum from Rockland. High $55 \mathrm{kDa}$ protein levels were identified in A549 cells and a lower amount in Hela, PC3, CA46 and HL-60 cell lines whereas no protein levels were observed in MCF-7 cell line from breast cancer and in MRC-5 from normal lung tissue. An anti- $ß$-actin antibody was used for a loading control. (b) Protein extracts from cellular supernatant of non-small cell lung cancer A549 and cell lysate from A549 and MRC-5 cells were loaded into SDS gel and subjected to electrophoresis and immunoblotting with the polyclonal anti-RTNKEASI serum from Rockland. A specific band at $55 \mathrm{kDa}$ was detected in the cellular supernatant sample with respect to cell lysate from A549; MRC-5 was used as negative control.

Since the MS analysis had also revealed matches with other ALDH isoforms (such as ALDH3A1), we hypothesized that these might add to the sensitivity of the assay. To this end, we performed further ELISA testings using a global ALDH assay without isoform specificity (Figures $4(\mathrm{c})$ and $4(\mathrm{~d})$ ). Remarkably, 33 out of 45 serum samples $(73.3 \%)$ showed positivity for global serum ALDH (>10 ng/ml). Only one patient from the cohort of patients with benign lung diseases showed ALDH serum positivity above this threshold, and all healthy donors were serum ALDH-negative. Interestingly, of 25 patients with early-stage NSCLC, 15 patients (60\%) showed elevated ALDH levels. Overall, serum ALDH levels were significantly elevated in the cohort of patients with NSCLC compared to patients without lung cancer. The mean difference in the ALDH concentration between no lung cancer and lung cancer is $13.90 \mathrm{ng} / \mathrm{ml}, 95 \% \mathrm{CI}: 8.45 \mathrm{ng} / \mathrm{ml}$ to $19.35 \mathrm{ng} / \mathrm{ml} ; p<0.001$. All the statistical analysis values are reported in Supplementary Materials (Table 1S and 2S).

According to the method of Pearson, neither ALDH1A1 nor ALDH concentration correlated significantly with the UICC stage ( $p=0.113$ and $p=0.359$, respectively).

\section{Discussion}

Worldwide, NSCL patients have the highest mortality between patients with solid tumors, and their prognosis is tightly stage-correlated. Nevertheless, conventional methods for the diagnosis of NSCLC have high costs and produce potentially false-positive outcomes. Thus, the discovery of highly sensitive, specific, noninvasive, and cost-effective lung cancer biomarkers to use in association with conventional approaches may increase the sensitivity of NSCLC screening $[4,6,45-47]$.

In this study, we show that the previously described TLP corresponds to ALDH1A1 and potentially other ALDH isoforms, which are highly expressed in NSCLC tissues [28, 33, 35-38, 46-49]. Since the peptide RTNKEASI did not linearly match ALDH isoform amino acid sequences, we concluded that it may structurally mimic these ALDH isoforms.

In our blood-based ELISA assays, we show that ALDH and, in accordance with Cao et al. [38], ALDH1A1 protein levels are statistically higher in patients with NSCLC compared to our nontumor cohort. However, only a small 
TABLE 2: Mass spectrometric identification of aldehyde dehydrogenase as $55 \mathrm{kDa}$ target of the anti-RTNKEASI serum.

\begin{tabular}{|c|c|c|c|c|}
\hline Gene symbol & Protein description & Unique peptides & Score & MW (kDa) \\
\hline \multicolumn{5}{|c|}{$55 \mathrm{kDa}$ band from A549 cell lysate excised from 1D gel } \\
\hline ALDH1A1 & Retinal dehydrogenase & 26 & 687 & 55.4 \\
\hline ALDH3A1 & Aldehyde dehydrogenase, dimeric NADP-preferring & 15 & 407 & 50.8 \\
\hline UGDH & UDP-glucose 6-dehydrogenase & 3 & 140 & 55.7 \\
\hline GSR & Glutathione reductase mitochondrial & 4 & 134 & 56.8 \\
\hline PDIA3 & Protein disulfide-isomerase A3 & 3 & 93 & 57.1 \\
\hline ALDH2 & Aldehyde dehydrogenase, mitochondrial & 3 & 83 & 56.9 \\
\hline \multicolumn{5}{|c|}{$55 \mathrm{kDa}$ band from A549 supernatant excised from 1D gel } \\
\hline ALDH1A1 & Retinal dehydrogenase 1 & 29 & 742 & 55.5 \\
\hline G6PD & Glucose-6-phosphate 1-dehydrogenase & 26 & 599 & 59.7 \\
\hline ALDH3A1 & Aldehyde dehydrogenase, dimeric NADP-preferring & 10 & 303 & 50.8 \\
\hline \multicolumn{5}{|c|}{$55 \mathrm{kDa}$ band from A549 immunoprecipitation excised from 1D gel } \\
\hline ALDH1A1 & Retinal dehydrogenase 1 & 28 & 351 & 55.5 \\
\hline G6PD & Glucose-6-phosphate 1-dehydrogenase & 12 & 223 & 59.7 \\
\hline ALDH3A1 & Aldehyde dehydrogenase, dimeric NADP-preferring & 3 & 70 & 50.8 \\
\hline \multicolumn{5}{|c|}{$55 \mathrm{kDa}$ spot 1 from A549 lysate excised from $2 \mathrm{D}$ gel } \\
\hline ALDH3A1 & Aldehyde dehydrogenase, dimeric NADP-preferring & 20 & 515 & 50.4 \\
\hline СCT2 & T-complex protein 1 subunit beta & 18 & 100.8 & 57.5 \\
\hline ALDH1A1 & Retinal dehydrogenase 1 & 12 & 57.4 & 54.8 \\
\hline ALDH1B1 & Aldehyde dehydrogenase X, mitochondrial & 11 & 52 & 57.2 \\
\hline \multicolumn{5}{|c|}{$55 \mathrm{kDa}$ spot 2 from A549 lysate excised from $2 \mathrm{D}$ gel } \\
\hline ALDH3A1 & Aldehyde dehydrogenase, dimeric NADP-preferring & 19 & 494.8 & 50.4 \\
\hline ALDH1A1 & Retinal dehydrogenase 1 & 19 & 120.45 & 54.8 \\
\hline
\end{tabular}

MW: molecular weight.
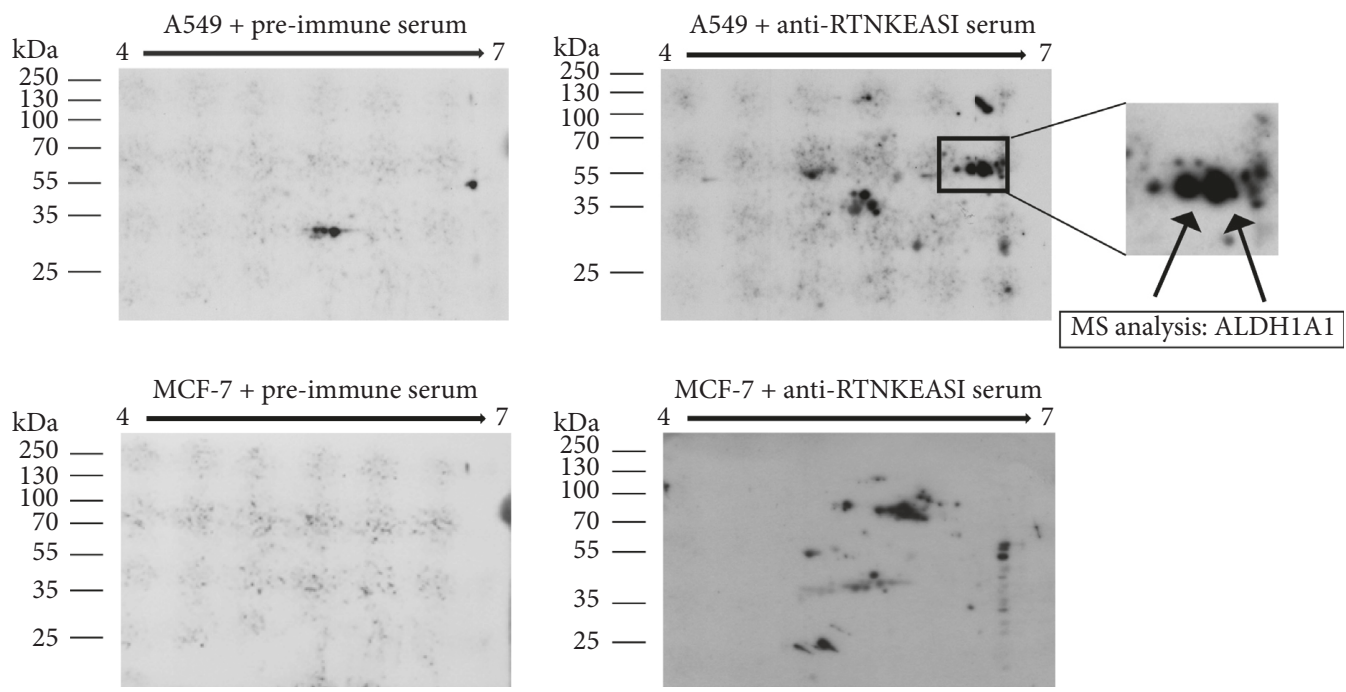

FIGURE 3: 2D gel electrophoresis and western blot analysis with cell lysates from A549 and MCF-7 cell lines using the polyclonal antiRTNKEASI serum and preimmune serum. Protein extract from A549 and MCF-7 cells were loaded in 2D gel followed by electrophoresis and transferred to PVDF for immunoblotting with the polyclonal anti-RTNKEASI serum or preserum. A rectangle marks the location of the ALDHs detected with the polyclonal anti-RTNKEASI serum in A549 cells; the reactive spots indicated with arrows were absent in MCF7 cells and in the blot incubated with the preserum. These protein spots at $55 \mathrm{kDa}$, excited and subjected to MS analysis, correspond to ALDH1A1.

percentage of NSCLC patients (6.7\%) display high ALDH1A1 serum levels, whereas sensitivity of the global ALDH test seems encouraging (73.3\%). This suggested that other ALDH isoforms are also released in the sera of NSCLC patients potentially adding to the sensitivity of this global assay. This finding is in accordance with previous studies showing that several ALDH isoforms are involved in NSCLC
[38]. ALDH3A1 is highly expressed in two types of NSCLC, adenocarcinoma and squamous cell carcinoma [48, 49]. ALDH3B1 expression was also found to be upregulated in a high percentage of human tumors, particularly in lung cancer [50]. Given the limited sample sizes of our cohorts, predictions on sensitivity and specificity of this marker are unreliable. However, it seems that the global ALDH test may 


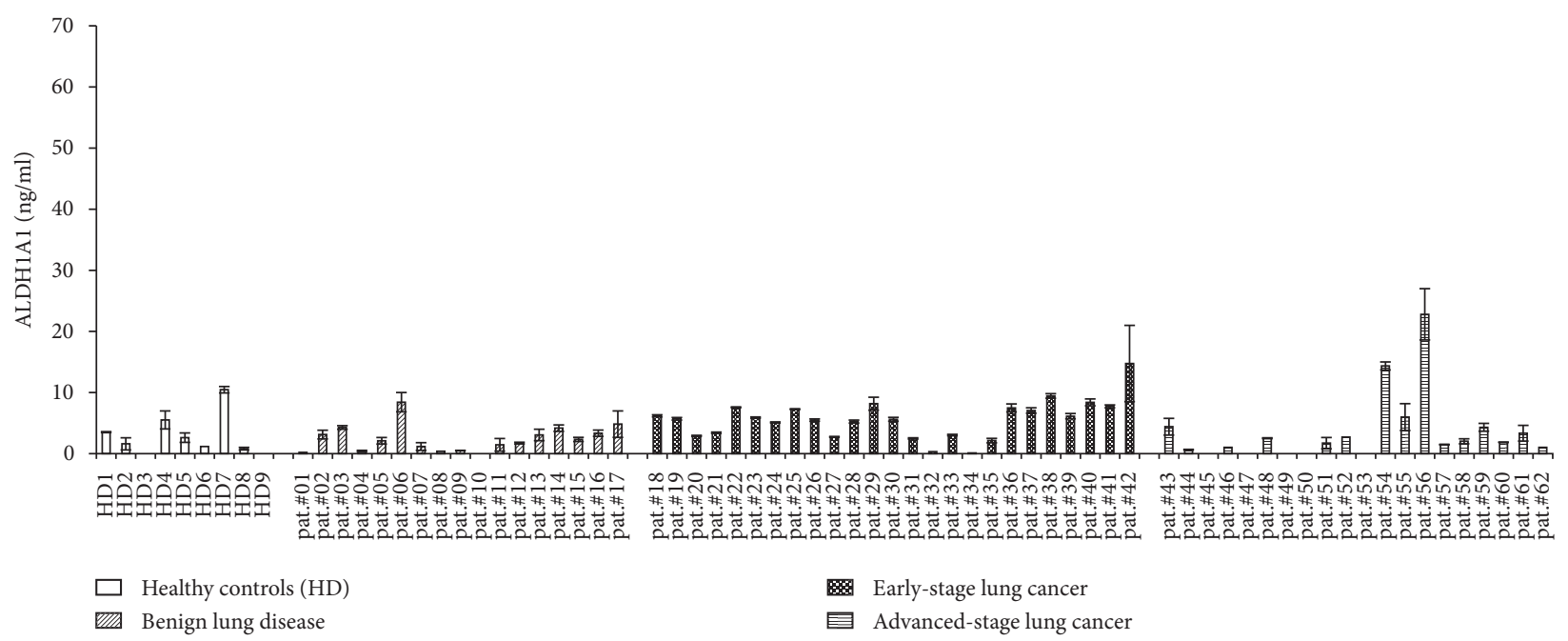

(a)

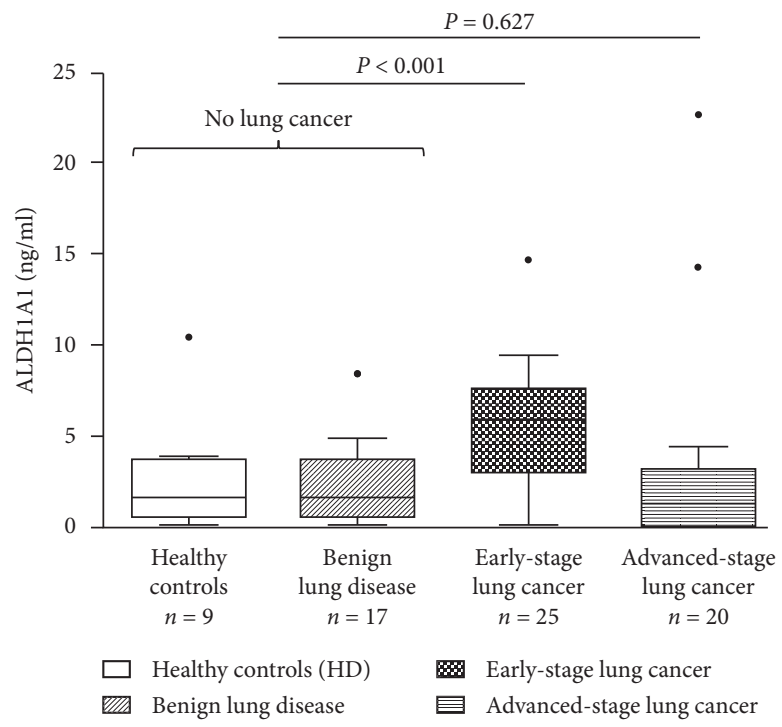

(b)

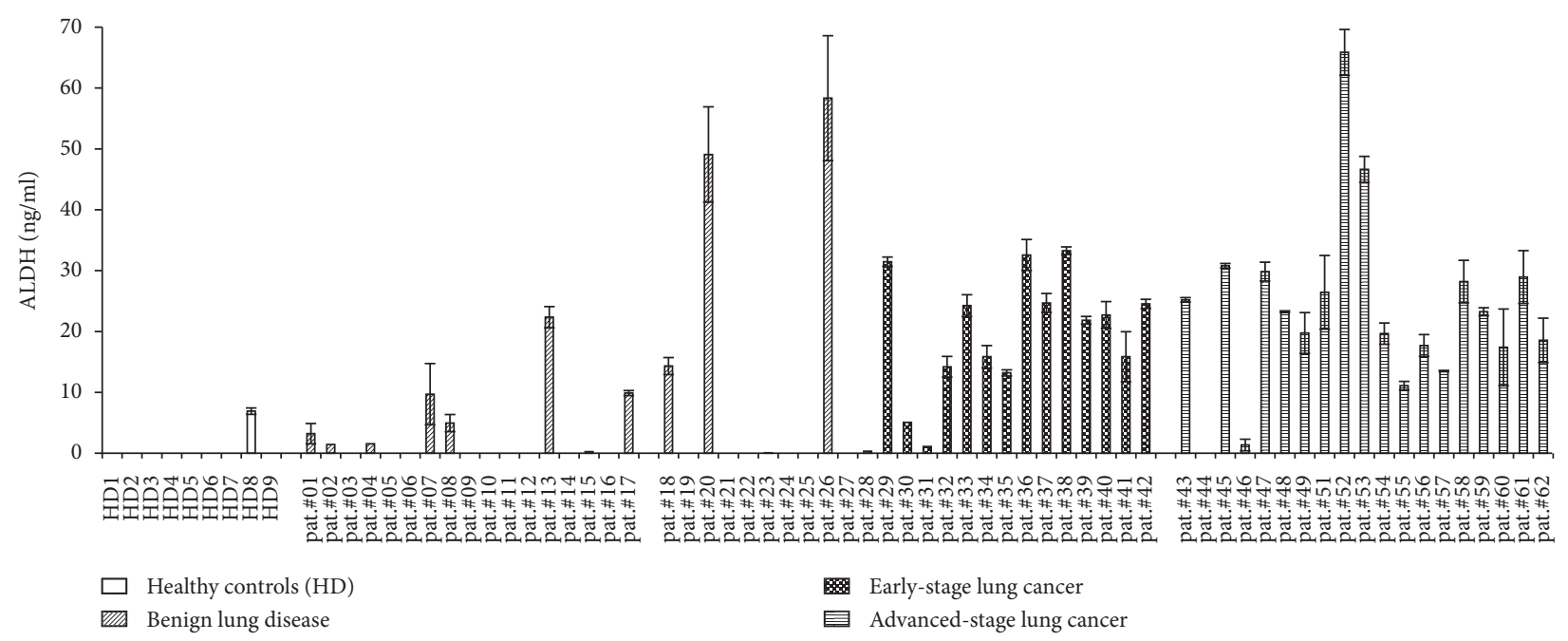

(c)

FIgUre 4: Continued. 


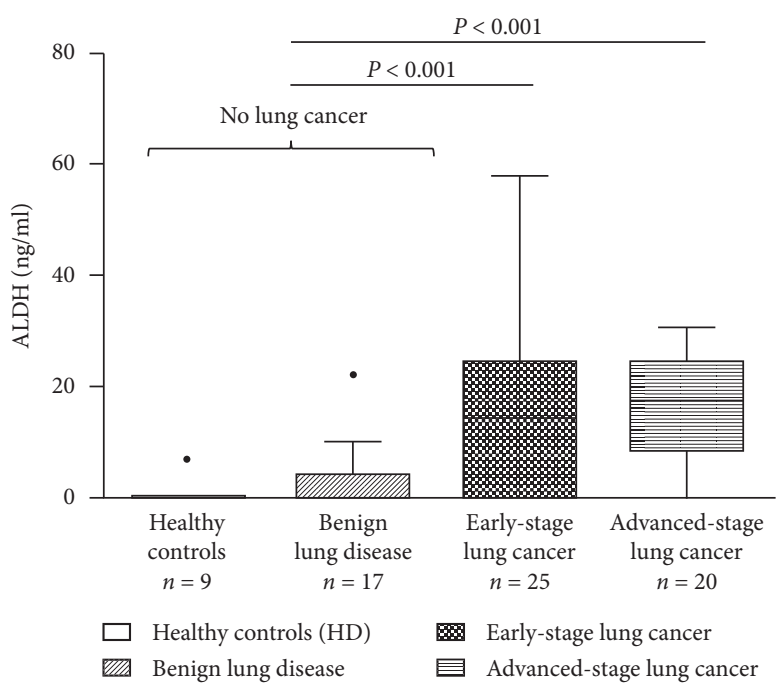

(d)

Figure 4: ELISA assay for sera (a, b) ALDH1A1 and (c, d) ALDHs. Sera samples from patients with NSCLC and benign lung pathologies and healthy donors were collected and subjected to an enzyme-linked immunosorbent assay with a monoclonal antibody recognizing specifically the isoform ALDH1A1 and all ALDH isoforms, respectively. (a) and (c) show individual data points, expressed as means \pm SD of 3 independent experiments, while (b) and (d) show summary statistics. Boxes and whiskers represent median and (interquartile) range. A backward stepwise linear-regression modelling was used to analyze differences in ALDH1A1 and ALDH concentrations between patients with and without lung cancer after precluding age, sex, and smoking (in pack-years) as nonsignificant independent covariables.

not significantly decrease specificity as compared to the ALDH1A1-specific test.

ALDH1A1 and ALDH3A1 expression levels in normal pneumocytes are significantly higher in tobacco smokers versus nonsmokers [48]. Although we did not identify any significant association between ALDH levels and smoking status across the cohorts, the higher expression levels in smokers may explain the trend towards higher ALDH levels in patients with benign lung pathologies (including a high percentage of patients with chronic obstructive pulmonary disease) compared to our nonsmoking healthy donors.

Our very small percentage of ALDH1A1-positive NSCLC patients $(6.7 \%)$ clearly contrasts with previously published work by Cao et al. [38] who detected a much higher percentage of ALDH1A1-positive NSCLC patients (55\%). This may be due to differences in ALDH1A1 kits, which presumably contain monoclonal antibodies with different specificity for ALDH1A1 but may also be explained in part by differences in the patient cohorts or different cutoff levels. Moreover, our results showed that some patients positive with ALDH1A1 were not with global ALDH, probably due to a potential degradation of these samples as global ALDH was performed later in time.

In conclusion, elevated ALDH serum levels can be detected in the vast majority of patients with early- and advanced-stage disease. Therefore, serum ALDH should be evaluated as part of a marker panel for noninvasive detection of early NSCLC in a larger cohort of patients at risk.

\section{Abbreviations}

TLP: $\quad$ Tumor liberated protein

ALDH: $\quad$ Aldehyde dehydrogenase
NSCLC: Non-small cell lung cancer

CT: $\quad$ Computed tomography

CEA: Carcinoembryonic antigen

NSE: $\quad$ Neuron-specific enolase

ALDH1A1: Aldehyde dehydrogenase isoform 1A1

PCA: $\quad$ Peptide completion assay

DTT: $\quad$ Dithiothreitol

PVDF: Polyvinylidene difluoride

CHAPS: 3-[(3-Cholamidopropyl) dimethylammonio]1-propanesulfonate

(ACN): Acetonitrile

FA: $\quad$ Formic acid

RSLC: $\quad$ Rapid separation liquid chromatography

DDA: Data-dependent mode

LC/MS: Liquid chromatography-mass spectrometry.

\section{Data Availability}

All data used to support the findings of this study are included within the article.

\section{Conflicts of Interest}

The authors declare that they have no conflicts of interest.

\section{Authors' Contributions}

$\mathrm{MB}$ and $\mathrm{AR}$ designed the study. AR collected the data. MV and AR analyzed the data. MV performed the statistical analysis. $\mathrm{MB}, \mathrm{AR}$, and $\mathrm{MV}$ interpreted the results. $\mathrm{MB}$ and AR drafted the manuscript with critical revisions from SL, $\mathrm{SH}, \mathrm{CB}$, and MR. SH conducted the mass spectrometry analysis. All authors approved the final version. 


\section{Acknowledgments}

This study was supported by the T. \& L. de Beaumont Bonelli Foundation for Cancer Research (to MB), a fellowship of the T. \& L. de Beaumont Bonelli Foundation for Cancer Research (to AR), and a professorship for immunological cancer research (to $\mathrm{MB}$ ) of the Hubertus Wald Foundation, Hamburg. The authors also thank Parnian Kiani for the assistance with the protein analysis via tandem MS and Astrid Huengsberg for the collection of patient samples.

\section{Supplementary Materials}

The first table describes the backward stepwise linear-regression analysis of the ALDH and ALDH1A1 ELISA assays, and the second table shows the mean values obtained in the related assay. (Supplementary Materials)

\section{References}

[1] R. Siegel, D. Naishadham, and A. Jemal, "Cancer statistics, 2013," CA: A Cancer Journal for Clinicians, vol. 63, no. 1, pp. 11-30, 2013.

[2] A. Jemal, F. Bray, M. M. Center, J. Ferlay, E. Ward, and D. Forman, "Global cancer statistics," CA: A Cancer Journal for Clinicians, vol. 61, no. 2, pp. 69-90, 2011.

[3] M. Yuxia, T. Zhennan, and Z. Wei, "Circulating miR-125b is a novel biomarker for screening non-small-cell lung cancer and predicts poor prognosis," Journal of Cancer Research and Clinical Oncology, vol. 138, no. 12, pp. 2045-2050, 2012.

[4] G. Tarro, "Immuno-therapy research," Immunotherapy Reseach Journal, vol. 1, pp. 1-2, 2017.

[5] S. Zhao, T. Jiang, L. Zhang et al., "Clinicopathological and prognostic significance of regulatory $\mathrm{T}$ cells in patients with non-small cell lung cancer: a systematic review with metaanalysis," Oncotarget, vol. 7, no. 24, pp. 36065-36073, 2016.

[6] G. Tarro, M. Paolini, and A. Rossi, "Molecular biology of lung cancer and future perspectives for screening," in Mass Spectrometry-Future Perceptions and Applications, pp. 1-16, IntechOpen, London, UK, 2019.

[7] N. I. Berlin, C. R. Buncher, R. S. Fontana, J. K. Frost, and M. R. Melamed, "The national cancer institute cooperative early lung cancer detection program. Results of the initial screen (prevalence). Early lung cancer detection: introduction," American Review of Respiratory Disease, vol. 130, no. 4, pp. 545-549, 1984.

[8] B. J. Flehinger, M. R. Melamed, M. B. Zaman, R. T. Heelan, W. B. Perchick, and N. Martini, "Early lung cancer detection: results of the initial (prevalence) radiologic and cytologic screening in the Memorial Sloan-Kettering study," American Review of Respiratory Disease, vol. 130, no. 4, pp. 555-560, 1984.

[9] J. K. Frost, W. C. Ball Jr., M. L. Levin et al., "Early lung cancer detection: results of the initial (prevalence) radiologic and cytologic screening in the Johns Hopkins study," American Review of Respiratory Disease, vol. 130, no. 4, pp. 549-554, 1984.

[10] R. S. Fontana, D. R. Sanderson, W. F. Taylor et al., "Early lung cancer detection: results of the initial (prevalence) radiologic and cytologic screening in the Mayo Clinic study," American Review of Respiratory Disease, vol. 130, no. 4, pp. 561-565, 1984.
[11] M. R. Melamed and B. J. Flehinger, "Screening for lung cancer," Chest, vol. 86, no. 1, pp. 2-3, 1984.

[12] R. S. Fontana, D. R. Sanderson, L. B. Woolner, W. F. Taylor, W. E. Miller, and J. R. Muhm, "Lung cancer screening: the Mayo program," Journal of Occupational and Environmental Medicine, vol. 28, no. 8, pp. 746-750, 1986.

[13] A. Kubík and J. Polák, "Lung cancer detection results of a randomized prospective study in Czechoslovakia," Cancer, vol. 57, no. 12, pp. 2427-2437, 1986.

[14] P. M. Marcus, E. J. Bergstralh, R. M. Fagerstrom et al., "Lung cancer mortality in the Mayo Lung Project: impact of extended follow-up," JNCI Journal of the National Cancer Institute, vol. 92, no. 16, pp. 1308-1316, 2000.

[15] P. M. Marcus, E. J. Bergstralh, M. H. Zweig, A. Harris, K. P. Offord, and R. S. Fontana, "Extended lung cancer incidence follow-up in the Mayo Lung Project and overdiagnosis," JNCI: Journal of the National Cancer Institute, vol. 98 , no. 11 , pp. 748-756, 2006.

[16] D. R. Aberle, S. DeMello, C. D. Berg et al., "Results of the two incidence screenings in the national lung screening trial," New England Journal of Medicine, vol. 369, no. 10, pp. 920-931, 2013.

[17] P. Leidinger, A. Keller, S. Heisel et al., "Identification of lung cancer with high sensitivity and specificity by blood testing," Respiratory Research, vol. 11, no. 1, p. 18, 2010.

[18] D. Schottenfeld, "Patient risk factors and the detection of early cancer," Preventive Medicine, vol. 1, no. 3, pp. 335-351, 1972.

[19] H.-Y. Wu, Y.-G. Goan, Y.-H. Chang et al., "Qualification and verification of serological biomarker candidates for lung adenocarcinoma by targeted mass spectrometry," Journal of Proteome Research, vol. 14, no. 8, pp. 3039-3050, 2015.

[20] S. Begum, M. Brait, S. Dasgupta et al., "An epigenetic marker panel for detection of lung cancer using cell-free serum DNA," Clinical Cancer Research, vol. 17, no. 13, pp. 4494-4503, 2011.

[21] G. Tarro, C. Esposito, A. Perna, P. P. Claudio, and A. Giordano, "Immunohistochemical characterization of tumor liberated particles (TLP) expression pattern in lung cancer," Anticancer Research, vol. 18, no. 4A, pp. 2365-2370, 1998.

[22] G. Tarro, A. Pederzini, G. Flaminio, and S. Maturo, "Human tumor antigens inducing in vivo delayed hypersensitivity and in vitro mitogenic activity," Oncology, vol. 40, no. 4, pp. 248-254, 1983.

[23] G. Tarro, "Tumor liberated protein from lung cancer and perspectives for immunotherapy," Journal of Cellular Physiology, vol. 221, no. 1, pp. 26-30, 2009.

[24] G. Tarro, "Characterization of a fragment containing a putative TLP cDNA sequence," Anticancer Research, vol. 22, no. 5, pp. 2693-2696, 2002.

[25] C. Esposito, G. Tarro, N. Cuomo, A. Di Spirito, and F. Morelli, "Anti-TLP antibodies in lung cancer patients," Internal Medicine, vol. 5, pp. 191-194, 1997.

[26] G. Tarro, A. Perna, and C. Esposito, "Early diagnosis of lung cancer by detection of tumor liberated protein," Journal of Cellular Physiology, vol. 203, no. 1, pp. 1-5, 2005.

[27] N. A. Sophos, A. Pappa, T. L. Ziegler, and V. Vasiliou, "Aldehyde dehydrogenase gene superfamily: the 2000 update," Chemico-Biological Interactions, vol. 130-132, no. 1-3, pp. 323-337, 2001.

[28] E. Meng, A. Mitra, K. Tripathi et al., "ALDH1A1 maintains ovarian cancer stem cell-like properties by altered regulation of cell cycle checkpoint and DNA repair network signaling," PLoS One, vol. 9, no. 9, Article ID e107142, 2014.

[29] N. E. Sládek, "Human aldehyde dehydrogenases: potential pathological, pharmacological, and toxicological impact," 
Journal of Biochemical and Molecular Toxicology, vol. 17, no. 1, pp. 7-23, 2003.

[30] Q. Zhang, A. Taguchi, M. Schliekelman et al., "Comprehensive proteomic profiling of aldehyde dehydrogenases in lung adenocarcinoma cell lines," International Journal of Proteomics, vol. 2011, Article ID 145010, 8 pages, 2011.

[31] D. Liang and Y. Shi, "Aldehyde dehydrogenase-1 is a specific marker for stem cells in human lung adenocarcinoma," Medical Oncology, vol. 29, no. 2, pp. 633-639, 2012.

[32] A. López-González, C. Salas, M. Provencio, M. Córdoba, and C. Gamallo, "Aldehyde dehydrogenases in early stage lung cancer: nuclear expression," Clinical and Translational Oncology, vol. 16, no. 10, pp. 931-934, 2014.

[33] Y. Qiu, T. Pu, L. Li et al., "The expression of aldehyde dehydrogenase family in breast cancer," Journal of Breast Cancer, vol. 17, no. 1, pp. 54-60, 2014.

[34] D. Ran, M. Schubert, I. Taubert et al., "Heterogeneity of leukemia stem cell candidates at diagnosis of acute myeloid leukemia and their clinical significance," Experimental Hematology, vol. 40, no. 2, pp. 155-165.e1, 2012.

[35] Y. Xing, D.-Y. Luo, M.-Y. Long, S.-L. Zeng, and H.-H. Li, "High ALDH1A1 expression correlates with poor survival in papillary thyroid carcinoma," World Journal of Surgical Oncology, vol. 12, no. 1, p. 29, 2014.

[36] X. Qian, S. Wagner, C. Ma et al., "Prognostic significance of ALDH1A1-positive cancer stem cells in patients with locally advanced, metastasized head and neck squamous cell carcinoma," Journal of Cancer Research and Clinical Oncology, vol. 140, no. 7, pp. 1151-1158, 2014.

[37] J. P. Sullivan, M. Spinola, M. Dodge et al., "Aldehyde dehydrogenase activity selects for lung adenocarcinoma stem cells dependent on notch signaling," Cancer Research, vol. 70, no. 23, pp. 9937-9948, 2010.

[38] Y.-T. Cao, J.-H. Li, Y.-T. Wang, Y.-W. Fu, and J. Xu, "Serum ALDH1A1 is a tumor marker for the diagnosis of non-small cell lung cancer," Tumori Journal, vol. 100, no. 2, pp. 214-218, 2014.

[39] G. Tarro, "From sequence of tumor liberated protein (TLP) to potential targets for diagnosis and therapy," Integrative Molecular Medicine, vol. 4, no. 3, pp. 1-3, 2017.

[40] A. Rossi, S. Schenone, A. Angelucci et al., "New pyrazolo-3,4d-pyrimidine derivative Src kinase inhibitors lead to cell cycle arrest and tumor growth reduction of human medulloblastoma cells," FASEB Journal, vol. 24, no. 8, pp. 2881-2892, 2010.

[41] J. Rahlff, M. Trusch, F. Haag et al., "Antigen-specificity of oligoclonal abnormal protein bands in multiple myeloma after allogeneic stem cell transplantation," Cancer Immunology, Immunotherapy, vol. 61, no. 10, pp. 1639-1651, 2012.

[42] G. Ak, Y. Tada, H. Shimada et al., "Midkine is a potential novel marker for malignant mesothelioma with different prognostic and diagnostic values from mesothelin," BMC Cancer, vol. 17, no. 1, p. 212, 2017.

[43] N. Willumsen, C. L. Bager, D. J. Leeming, A.-C. Bay-Jensen, and M. A. Karsdal, "Nidogen-1 degraded by cathepsin S can be quantified in serum and is associated with non-small cell lung cancer," Neoplasia, vol. 19, no. 4, pp. 271-278, 2017.

[44] A. Klupczynska, P. Dereziński, J. Matysiak, W. Dyszkiewicz, M. Kasprzyk, and Z. J. Kokot, "Determination of 16 serum angiogenic factors in stage I non-small cell lung cancer using a bead-based multiplex immunoassay," Biomedicine \& Pharmacotherapy, vol. 88, pp. 1031-1037, 2017.
[45] V. Brower, "Biomarker studies abound for early detection of lung cancer," JNCI Journal of the National Cancer Institute, vol. 101, no. 1, pp. 11-13, 2009.

[46] Y. Zhou, Y. Wang, X. Ju et al., "Clinicopathological significance of ALDH1A1 in lung, colorectal, and breast cancers: a meta-analysis," Biomarkers in Medicine, vol. 9, no. 8, pp. 777-790, 2015.

[47] P. Marcato, C. A. Dean, R.-Z. Liu et al., "Aldehyde dehydrogenase $1 \mathrm{~A} 3$ influences breast cancer progression via differential retinoic acid signaling," Molecular Oncology, vol. 9, no. 1, pp. 17-31, 2015.

[48] M. Patel, L. Lu, D. S. Zander, L. Sreerama, D. Coco, and J. S. Moreb, "ALDH1A1 and ALDH3A1 expression in lung cancers: correlation with histologic type and potential precursors," Lung Cancer, vol. 59, no. 3, pp. 340-349, 2008.

[49] J. S. Moreb, H. V. Baker, L.-J. Chang et al., "ALDH isozymes downregulation affects cell growth, cell motility and gene expression in lung cancer cells," Molecular Cancer, vol. 7, no. 1, p. $87,2008$.

[50] S. A. Marchitti, D. J. Orlicky, C. Brocker, and V. Vasiliou, "Aldehyde dehydrogenase 3B1 (ALDH3B1): immunohistochemical tissue distribution and cellular-specific localization in normal and cancerous human tissues," Journal of Histochemistry and Cytochemistry, vol. 58, no. 9, pp. 765-783, 2010. 


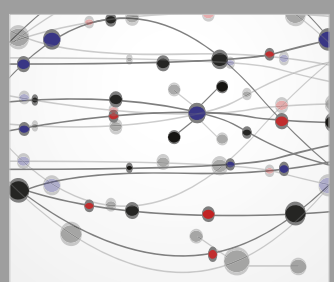

The Scientific World Journal
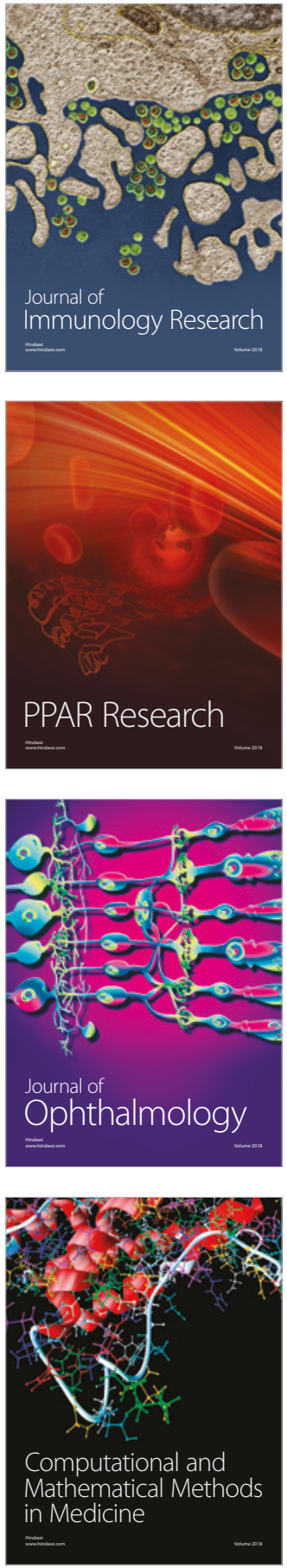

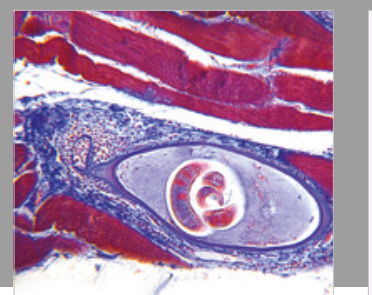

Gastroenterology Research and Practice

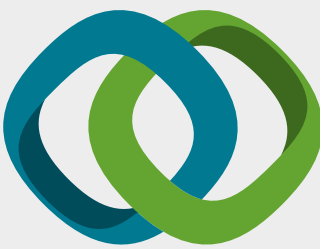

\section{Hindawi}

Submit your manuscripts at

www.hindawi.com
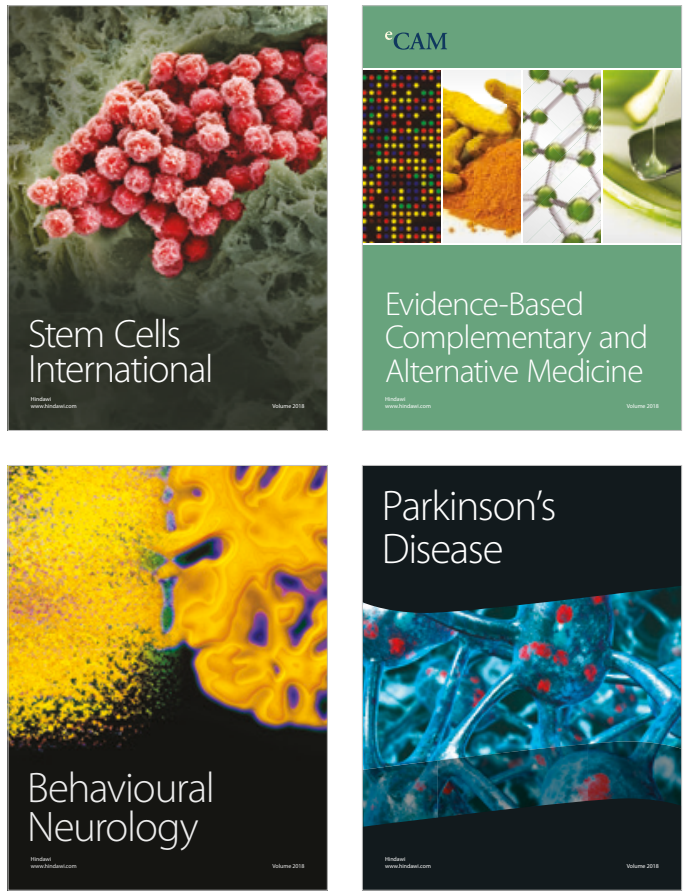

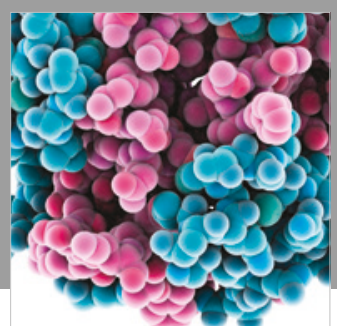

ournal of

Diabetes Research

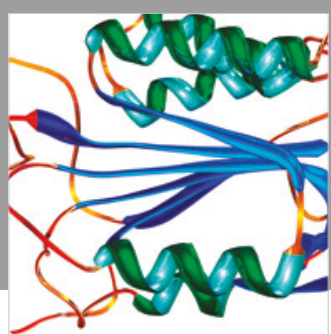

Disease Markers
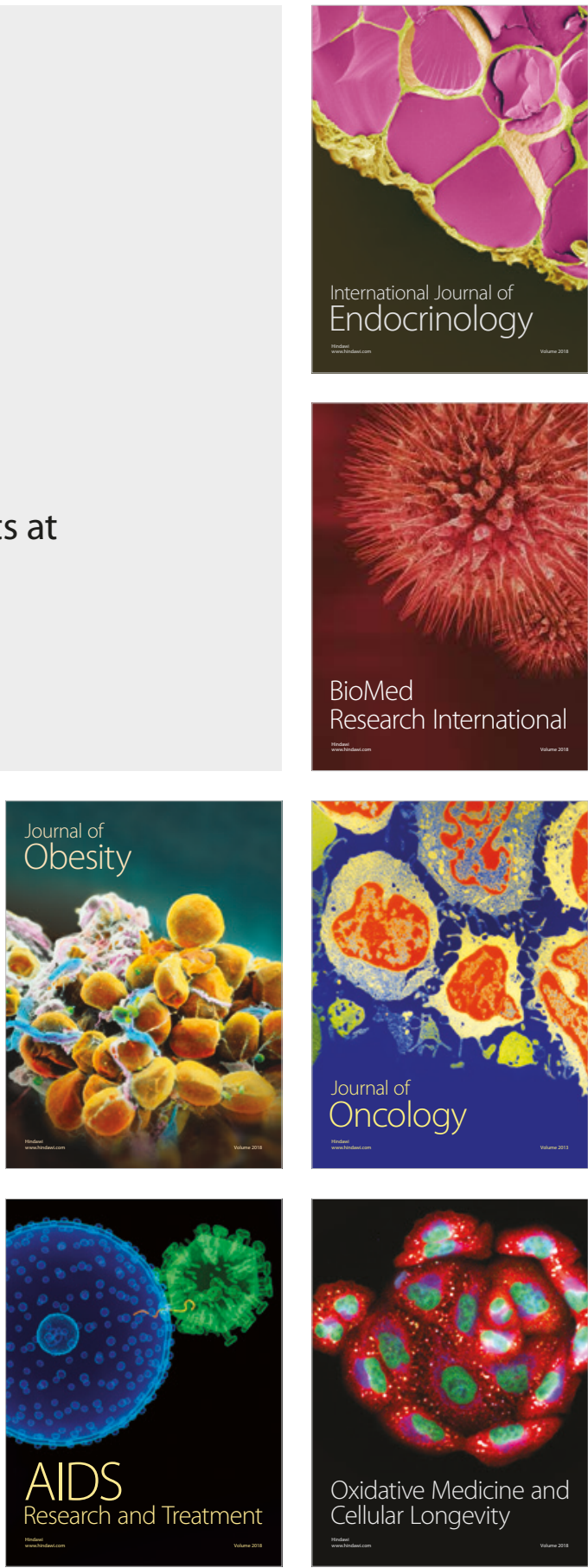